\title{
Cold spray technology: future of coating deposition processes
}

\author{
Harminder Singh \\ Guru Nanak Dev University, Regional Campus, Jalandhar, Punjab-144007, India \\ harminder10@gmail.com
}

T.S. Sidhu

Shaheed Bhagat Singh College of Engg. \& Tech., Ferozepur, Punjab, India

S.B.S. Kalsi

Amritsar College of Engineering \& Technology, Amritsar, Punjab, India

\begin{abstract}
Cold spray (CS) belongs to a wide family of thermal spray technology with the difference that it is a solid state process in which spray particles are deposited via supersonic velocity impact at a temperature much below the melting point of the spray material. This paper briefly describes the various aspects of this rapidly emerging technology, with almost all the important parameters which affect the deposition behavior along with advantages and limitations; applications and history of emergence of this process is also reviewed. Though this technology emerges three decades ago but still it could not establish itself as viable practical industrial technology. Hence, the efforts, along with funding from public/private sources are required to commercialize this coating process. It is expected that next decade will saw the growth of cold spray as a viable coating process around the globe.
\end{abstract}

KEYWORDS. Cold Spray; Thermal Spray; Coating; Corrosion.

\section{INTRODUCTION}

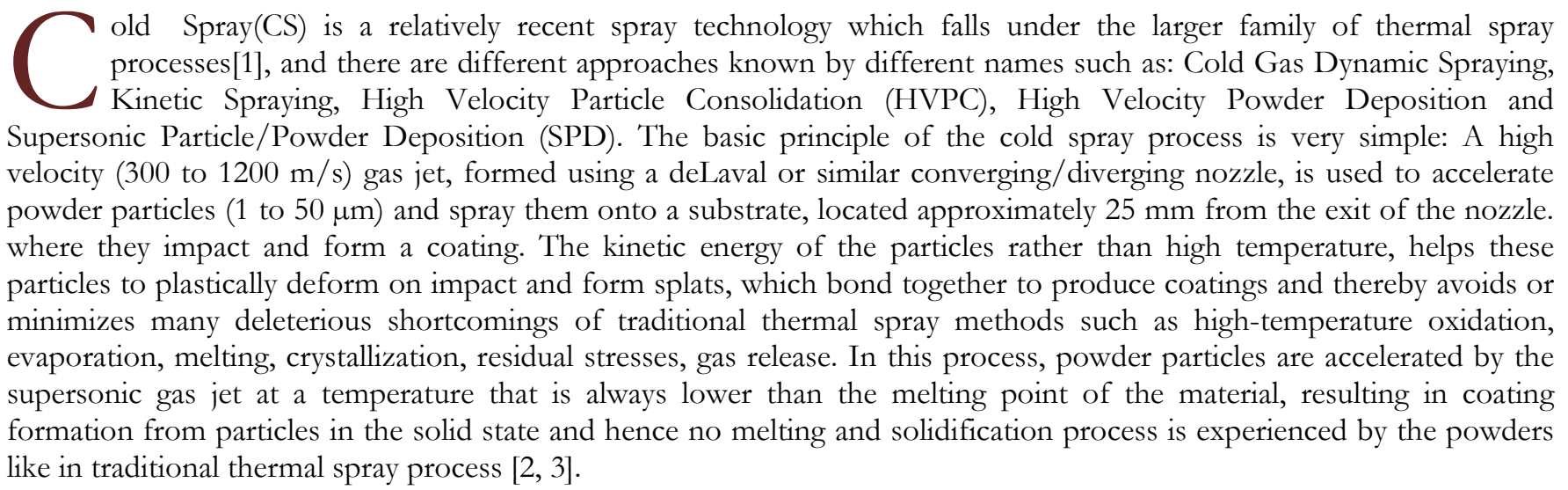


Moreover, the footprint of the cold spray beam is very narrow typically around $5 \mathrm{~mm}$ diameter due to small size of the nozzle (10-15 $\left.\mathrm{mm}^{2}\right)$ and spray distance $(5-25 \mathrm{~mm})$, yielding a high-density particle beam, results in precise control over the area of deposition over the substrate surface. This process is similar to a micro shot peening and hence the coatings are produced with compressive stresses, rather than tensile stresses, which results in dense and ultra thick (5-50 mm) coatings without adhesion failure. The low temperature formation of coating leads to oxides and other inclusions -free coatings with wrought-like microstructure [2].

\section{COLD SPRAY (CS) SYSTEM}

$\mathrm{T}$ he CS system can be designed in either portable or manual and robotic or fixed systems. The gasses having aerodynamic properties are generally used to propel the powder particles, as: 1) Helium 2) Nitrogen 3) Mixture of $\mathrm{He}$ and $\left.\mathrm{N}_{2} 4\right)$ Dry air $\left(79 \% \mathrm{~N}_{2}-21 \% \mathrm{O}_{2}\right)$

The main components of CS system includes [4]:

$\checkmark$ Powder feeder (powders used are in the range of 1 to $50 \mu \mathrm{m}$ in diameter)

$\checkmark$ Source of a compressed gas

$\checkmark$ Gas heater to preheat the gas, to compensate for the cooling due to rapid expansion in nozzle

$\checkmark$ Supersonic nozzle (Delaval nozzle)

$\checkmark$ Spraying chamber with a motion system

$\checkmark$ System for monitoring and controlling spray parameters (to measure and control the gas temperature and pressure)

\section{TYPES OF CS SYSTEM}

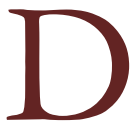

uring the practical development of cold spray technology, two methods of injecting the spray materials into the nozzle were patented, leading to what is known today as high pressure cold spray (HPCS) and low pressure cold spray (LPCS) system. The two main distinctions of these two systems are; the utilisation of 5-10 bars pressure gas in LPCS instead of 25-30 bars in HPCS and the radial injection of powder in LPCS instead of axial injection in HPCS $[1,4]$.

\section{Low Pressure Cold Spray (LPCS)}

In low-pressure cold spray the accelerating gas, usually air or nitrogen, at relatively low pressure (5-10 bar) and preheated (up to $550^{\circ} \mathrm{C}$ ), within the gas heater to optimize its aerodynamic properties, and then forced through a 'DeLaval' nozzle. At the diverging side of the nozzle, the heated gas is accelerated to about in the range of 300 to $600 \mathrm{~m} / \mathrm{s}$. Solid powder particles are radially introduced downstream of the throat section of the supersonic nozzle and accelerated toward the substrate as shown in the Fig.1of the LPCS system. The feedstock particles are effectively drawn in from the powder feeder by Venturi effect, i.e. by keeping the static pressure within the nozzle below the atmospheric pressure. This is achieved if the ratio of the cross-sectional area of the supersonic nozzle at the powder entry point, $\mathrm{Ai}\left(\mathrm{m}^{2}\right)$ to that of the throat $\left(\mathrm{A}^{*}\right)$ satisfies following equation: $\mathrm{Ai} / \mathrm{A}^{*} \geq 1.3 \mathrm{Po}+0.8$ where; $\mathrm{Po}=$ gas pressure at the nozzle inlet (MPa) [4].

Due to the elimination of the need of a high pressure delivery system in LPCS, there is improvement in its operational safety, system is more portable, flexible in automation, and spraying cost also reduced significantly than a HPCS system, but the deposition efficiency with this system typically do not exceed $50 \%$. Also in this system the powder particles does not pass through the throat, hence wear of the nozzle walls occurs only in the supersonic portion of the nozzle and, this ensures a longer service life of the nozzle. Additionally, a LPCS system is more compatible with a number of system modifications.

\section{High Pressure Cold Spray (HPCS)}

In high-pressure cold spray, the accelerating gas helium or nitrogen at high pressure (25-30 bar) is preheated (up to 1000 ${ }^{\circ} \mathrm{C}$ ) to optimise its aerodynamic properties (not to increase particle temperature) and then forced through a convergingdiverging 'DeLaval' nozzle. At the nozzle, the expansion of the gas produces the conversion of enthalpy into kinetic energy, which accelerates the gas flow to supersonic regime $(1200 \mathrm{~m} / \mathrm{s})$ while reducing its temperature. The solid powder feedstock particles mix with the propellant gas in the pre-chamber zone and are then axially fed into the gas stream, upstream of the converging section of the nozzle at a higher pressure than the accelerating gas to prevent backflow of the carrier gas to the powder feeder as shown in Fig. 2. The accelerated solid particles (600 to $1200 \mathrm{~m} / \mathrm{s}$ ) impact the substrate 
with enough kinetic energy to induce mechanical and/or metallurgical bonding. The spray efficiency in this HPSC system is very high, reaching up to $90 \%$ as compared to $50 \%$ in LPSC system.

Moreover, the temperature of particles remain substantially below the initial gas preheat temperature due to short contact time of spray particles with the hot gas called dwell time and hence the name cold spray coating [4].

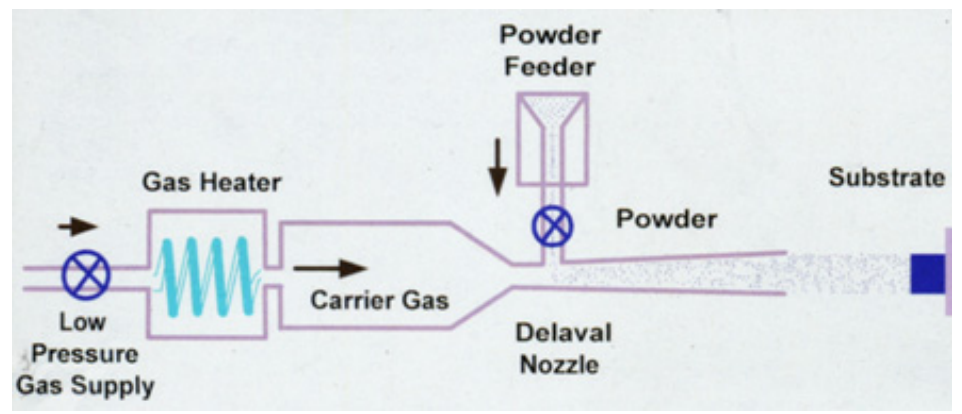

Figure 1: Operating principle of low-pressure coldspray [1].

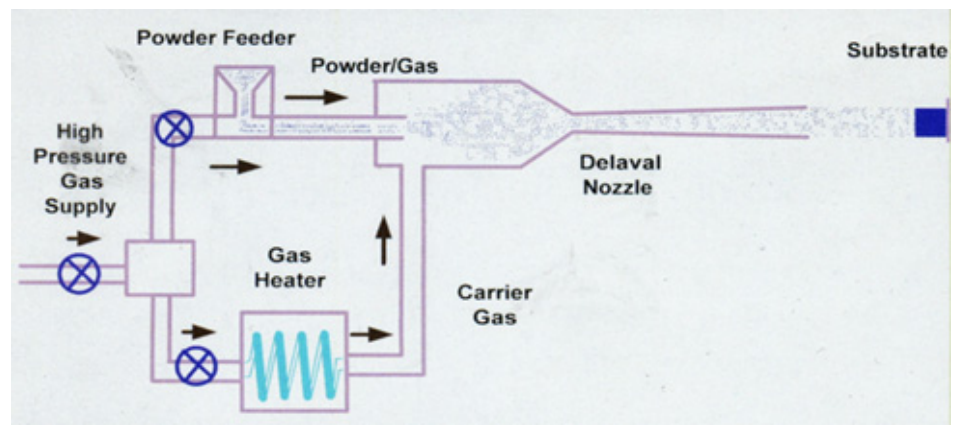

Figure 2: Operating principle of high-pressure coldspray [1].

\section{HISTORY OF THE INVENTION (1900-2011)}

he basic idea behind cold spray is fairly simple and the concept has already been patented in the early $20^{\text {th }}$ century. The invention of the cold spray process can be dated back to the time of the invention of the thermal spray process by Schoop. Though, the idea of using the impact energy of the particles to produce a coating using a carrier gas jet to accelerate solid particles had been in use for a century or more. However, the technology needed to put the idea into practical use was complex at the time and required further development. Consequently, it took 80 years for its first demonstration that happened accidentally during a two-phase flow gas dynamic experiment in Russia. The cold spray technique can also be viewed as an offshoot of the cold war between the superpowers. While studying models subjected to a supersonic two-phase flow (gas + solid particles) in a wind tunnel at Russian Academy of Science, scientists observed that during the impact of particles of various sizes, impact angles, and velocities on various materials, the solid particles deposited onto the surface when the velocity of impact was higher than certain critical value. Since then, efforts have been devoted for the development of this process into a practical industrial technology and the number of related patents and research publications has grown exponentially. A brief view of the development of this process from 1900 to present is as follows [5]:

1902: On August 12, 1902, Thurston patented, "A method for carrying out the process of coating one metal with another".

1915: March 30, 1915 Schoop patented thermal spray process.

Schoop developed the process wherein molten metal droplets are sprayed onto a surface to produce the coating, viz., the thermal spray process, when he observed that if mud balls are shot onto a wall, they get deposited on impact onto the wall forming a mud deposit.

However, during this invention he overlooked the impact energy in the mud balls that led to deposit formation. If Schoop had taken note of the basic phenomenon of his invention, solid state deposition by impact energy, Cold Spray would have been the first thermal spray process and not the most recent one. 


\section{0 -1980:}

In the late 1980s, Alkhimov, Anatoli Papyrin and their team at Institute of Theoretical and Applied Mechanics of the Siberian Division of the Russian Academy of Science (ITAM of RAS) in Novosibirisk, developed a "method of applying coating", by converting the wind tunnel experiments into a viable coating technique and patented it.

\section{0-2000:}

$\checkmark$ A U.S. government sponsored collaborative research and development agreement (CRADA) under the National Center for Manufacturing Sciences (NCMS) brought cold spray out of Russia. Under this CRADA, Anatoli Papyrin, the leader of the cold spray group in Russia, moved to the U.S., built a system at NCMS, and carried out basic studies. Albert Kay, ASB Industries, visited NCMS and bought the license to build cold spray systems and use them for supplying industrial coatings.

$\checkmark$ Heinrich Kreye, German Armed Forces University, Hamburg, did a large and exhaustive study on all aspects of the cold spray process, including theory, modeling, design and development of guns and nozzles, preparation and characterization of coatings, and development of application coatings. German Aerospace Industry (EADS) also initiated cold spray research directed towards both protective coatings and fabrication of bulk forms.

So, during this period the cold spray process developed into an engineered coating process and modeling studies were taken up and various diagnostic techniques were developed to understand and enhance performance of this process. Systematic spray optimization experiments were executed to produce and characterize various coating materials.

2000- 2006:

Germany realized that the availability of a reliable cold spray system to produce reproducible coatings was of paramount importance and that cold spray system development is a multi-disciplinary one. Hence, they formed a consortium of Federal Armed Forces University, Hamburg; Linde R \& D; and CGT Technologies to pool their respective specialties in materials science, gas technology and process control equipment to evolve the Kinetic 3000 cold spray system. A large number of spray experiments were carried out, which resulted in many industrial applications including the world's first mass production application of the cold spray process, viz., thermal management layers on high performance heat sinks.

\section{6-Present:}

At the present time the Cold Spray method is recognized by world leading scientists and specialists. A wide spectrum of research is being conducted at many research centres and companies in many countries and it has been established as a viable coating process to produce protective coatings, performance enhancing layers, ultrathick coatings, freeforms, and near net shapes. Governments of various countries have realized the importance of this technology and various projects are sanctioned to commercialize this technology. Recent study concentrate on optimizing cold spray parameters to produce coatings of many materials with desired microstructures.

PARTICLE VELOCITY $\left(10^{\wedge} 3 \mathrm{ft} / \mathrm{s}\right)$

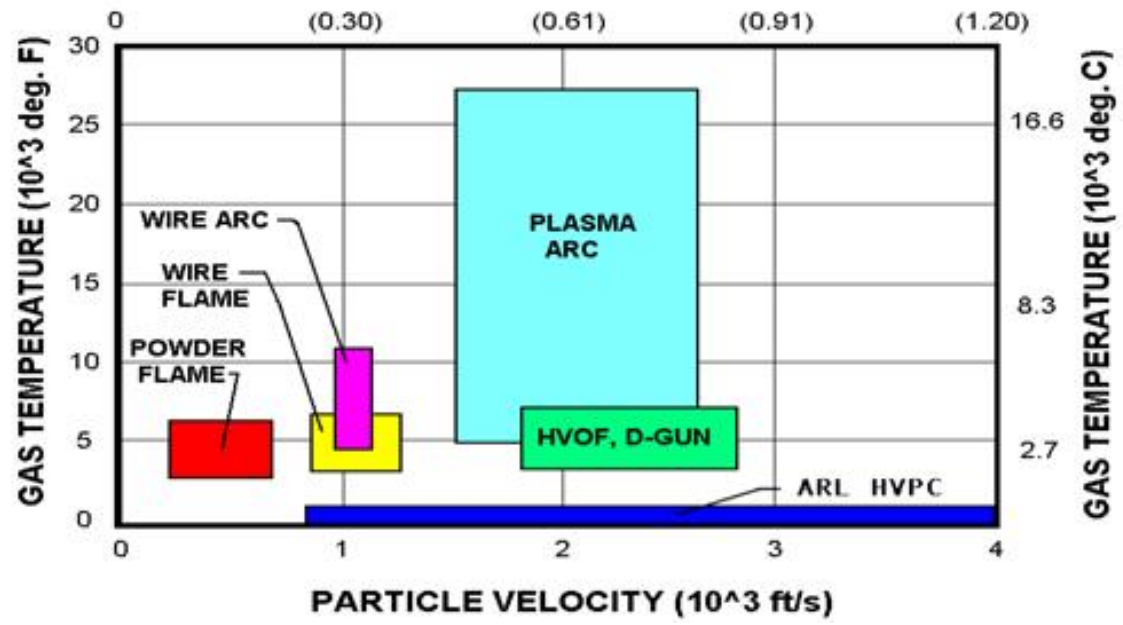

Figure 3: Comparison between different thermal spraying processes[30]. 


\section{Advantages OF CS}

$\mathrm{C}$ oating technology has rapidly advanced with the addition of cold spray coating techniques. The major advantage over thermal spray techniques are the low temperatures involved which minimize any potential phase change and keep the particles in their unmodified solid state. The difference between the Cold Spray Process(HVPC) and other thermal spray processes is illustrated in Fig. 3. In the thermal spray process, a coating is formed by melting the coating material and then quenching the molten droplets. Hence thermal sprayed coatings in general have microstructures with varying degrees of porosity, oxides and other inclusions, and low corrosion resistance characteristics [2]. However, CS process has advantage of metal deposition with low heat input, local deposition to limited area, and deposition free of oxides and other inclusions can be produced to any metal surface, and due to compressive stresses, the dense uniform deposit of any thickness with wrought-like microstructure are obtained. Moreover, the oversprayed expensive raw material can be collected for reprocessing $[2,6]$.

\section{MECHANISM OF COLD SPRAY PROCESS}

he bonding mechanism in thermal spraying can be explained by the occurrence of local adiabatic shear instabilities,at particle-substrate and particle-particle interfaces due to thermal softening, however the true bonding mechanism in cold spray process is still poorly understood [7, 8]. By means of a so-far widely accepted model; during impact, the solid particles undergoes plastic deformation, disrupt thin surface films (oxides), and in turn, intimate conformal contact is achieved and combined with high contact pressure, promotes bonding with the target surface[9, 10]. The common phenomena that have been observed during spraying onto various substrates are substrate and particle deformation, and substrate melting as there is evidence for the formation of a metal-jet [7, 11] as shown in Fig. 4, in which $20 \mu \mathrm{m}$ copper sphere impacting an aluminum plate at $650 \mathrm{~m} / \mathrm{s}$ is modeled. It shows the material adjacent to the interface behave as a viscous fluid-like, results in the formation of interfacial waves, roll-ups, and vortices [11].

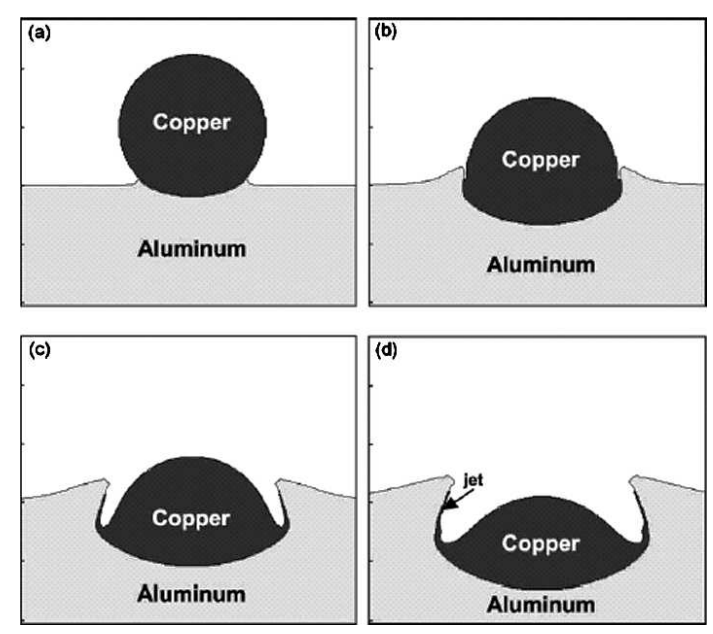

Figure 4: Impact of a Cu particle on a Cu substrate at successive times:(a) 5 ns, (b)20 ns, (c) 35 ns, (d) 50 ns [11].

It has been suggested that the adhesion strength of the particles in cold spraying is solely to their kinetic energy at impact, which is typically much less than the energy required to melt the particle and hence cold spray is a solid-state process [8, 9]. This concept is explained in the EDS image Fig.5 of cold sprayed copper deposit on aluminium substrate, examined by Champagne et al. [11]. It shows the forced mixing between the deposited copper (light area) and the aluminum substrate (dark region), and that can be achieved through deep-impact penetration of the copper into the aluminium [11]. This theory would also explain the minimum particle velocity necessary to achieve deposition, because sufficient kinetic energy must be available to plastically deform the solid material $[9,10]$. An empirical model by Champagne et al. [11] shows that interface mixing depends on the substrate hardness and coating material density, and the particle velocity $(\mathrm{m} / \mathrm{s}) \mathrm{Vp}$ needed for the attainment of interfacial mixing, as: $\mathrm{Vp}=\left[\left(7.5 \times 10^{4}\right)(\mathrm{B} / \mathrm{Q})\right]^{0.5}$, where $\mathrm{B}$ is the substrate Brinell hardness 
number and $\varrho$ is the particle density $\left(\mathrm{kg} / \mathrm{m}^{3}\right)$. Lupoi et al. [12] examined that during cold spray process Cu particles creates more erosion of substrate as compared to $\mathrm{Al}$ and $\mathrm{Sn}$, due to their low specific weight as compared to $\mathrm{Cu}$.
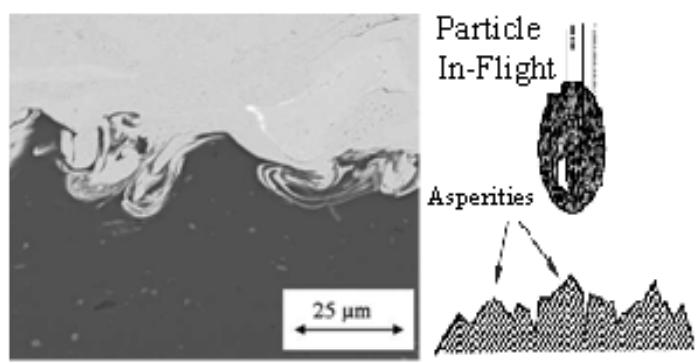

Substrate
Particle Mechanically

locked to asperities of a

substrate

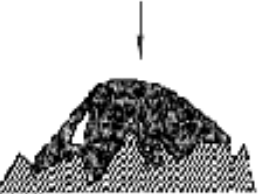

Figure 5: EDS image of $\mathrm{Cu}$ coating on $\mathrm{Al}$ [11] \& Schematic of mechanical locking [35].

\section{Particle Velocity (Vp) and Critical Velocity (VC)}

I t has been widely accepted that particle velocity $(\mathrm{Vp})$ prior to impact is one of the most important parameters in cold spraying. It determines whether deposition of a particle or erosion of a substrate occurs on the impact of a spray particle. Generally, for a given material, there exists a minimum particle velocity commonly known as critical velocity (Vc) which must be achieved for transition from erosion of the substrate to deposition of the particle occurs. Only those particles achieving a velocity higher than the critical one can be deposited to produce a coating $[2,7,13]$.

The three main stages for the cold spray coating build up and its relation with $\mathrm{Vp}$, Vc is shown as:

\begin{tabular}{|c|c|c|c|}
\hline $\begin{array}{l}\text { First } \\
\text { Stage/ } \\
\text { Initial } \\
\text { Stage }\end{array}$ & $\begin{array}{l}\text { Induction Time or Delay Time- The } \\
\text { time between the beginning of } \\
\text { surface treatment by the flow of } \\
\text { particles and the beginning of } \\
\text { particle attachment to the surface[7] }\end{array}$ & $\begin{array}{l}\checkmark \mathrm{Vp}<\mathrm{Vc}, \text { particles simply } \\
\text { reflect (bounce) off the } \\
\text { surface. [2] } \\
\checkmark \mathrm{Vp}=\mathrm{Vc} \text {, then solid particle } \\
\text { erosion of the surface } \\
\text { occurs without any } \\
\text { deposition. }\end{array}$ & $\begin{array}{l}\text { Fig. } 7 \text { shows three regions, divided by } \\
\text { two values of particle velocity: vcr1 and } \\
\text { vcr2 [7] } \\
\text { 1. } \mathrm{Vp}<\mathrm{vcr} 1 \text {, large number of particle } \\
\text { impacts before their adherence to the } \\
\text { surface. } \\
\text { 2. } \mathrm{vcr} 1<\mathrm{Vp}<\mathrm{vcr} 2 \text {, particles adhere to }\end{array}$ \\
\hline $\begin{array}{l}\text { Second } \\
\text { Stage }\end{array}$ & $\begin{array}{l}\text { Particles plastically deform and } \\
\text { adhere to the substrate and a first } \\
\text { thin layer of the particle material is } \\
\text { formed [7], Fig.6 }\end{array}$ & $\begin{array}{l}\text { Vc depends upon the } \\
\text { combinations of spray } \\
\text { materials and the substrates } \\
{[14]}\end{array}$ & $\begin{array}{l}\text { the surface only after some delay. } \\
\text { 3. Vp }>\text { vcr2 }(850 \mathrm{~m} / \mathrm{s}) \text {, particles adhere } \\
\text { to the initial surface without any Delay } \\
\text { Time. }\end{array}$ \\
\hline $\begin{array}{l}\text { Third } \\
\text { Stage }\end{array}$ & $\begin{array}{l}\text { The particles interact with the } \\
\text { surface formed by previously } \\
\text { incident particles in second stage } \\
\text { It's a build-up stage, characterized } \\
\text { by the growing thickness of the } \\
\text { coating layer[7] }\end{array}$ & $\begin{array}{l}\text { Vc different from the Second } \\
\text { stage, as this corresponds to } \\
\text { the spray material impacting } \\
\text { on the substrate of the same } \\
\text { compositions as the powder } \\
{[14]}\end{array}$ & $\begin{array}{l}\text { There is the up-limit to the velocity, } \\
\text { over which a strong erosion is } \\
\text { generated. } \\
\text { Coating build-up only if Vp less than up- } \\
\text { limit velocity. With most spray materials } \\
\text { the up-limit velocity is higher than } 1000 \\
\mathrm{~m} / \mathrm{s} \text { [14] }\end{array}$ \\
\hline
\end{tabular}

The critical particle velocity, as reported by many authors $[2,7,13,14,15]$ changes with the spray material, approximately $560-580,620-640,620-640$ and $680-700 \mathrm{~m} / \mathrm{s}$, for $\mathrm{Cu}, \mathrm{Fe}, \mathrm{Ni}$ and $\mathrm{Al}$ respectively. However, there is variation in critical velocity is observed like for $\mathrm{Cu}$ as reported [11] critical velocity of $500 \mathrm{~m} / \mathrm{s}$ and $\mathrm{Li}$ et al. [16] examined in the range from 298 to $356 \mathrm{~m} / \mathrm{s}$. This variation of $\mathrm{Vc}$ is due to its dependence on many factors mostly on the thermo-mechanical properties of the substrate and the spray powder material and the particle velocity $\mathrm{Vp}$ is a function of the spray conditions, including physical properties or nature of the driving gas, its operating temperature and pressure and nozzle design of the spray gun and material properties, such as particle diameter, size distribution of particles in powder, density and morphology of powder $[2,7,13,14,15]$. 


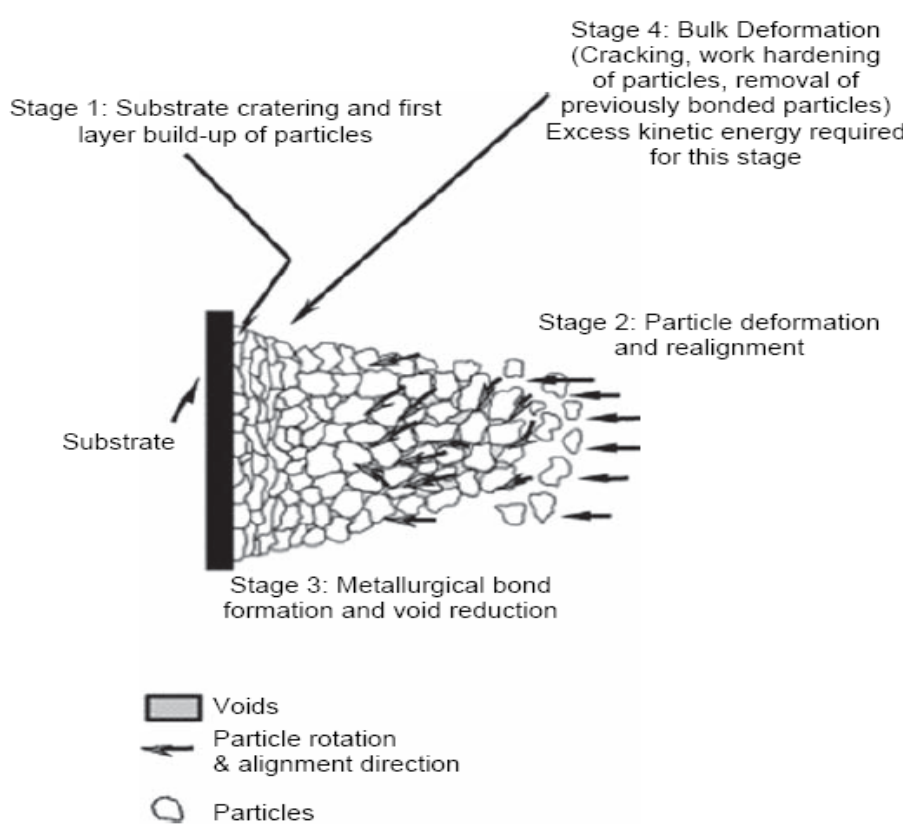

Figure 6: The schematic view of different region of particles on substrate [7].

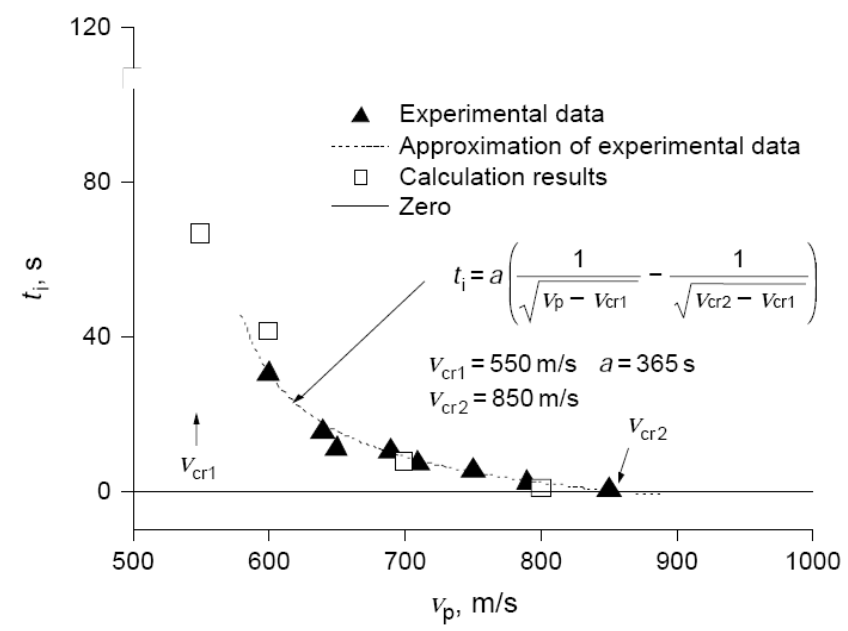

Figure 7: Induction (deposition delay) time vs. the mean impact velocity of $\mathrm{Al}$ particles on a polished $\mathrm{Cu}$ substrate [7].

\section{Splat Adhesion}

Cold spray process transfers momentum from the supersonic gas jet to the particles results in high velocity particle jet. These powder particles, on impact onto the substrate surface, plastically deform and once bonded to the substrate these particles are known as splats. The interlinking of these splats build up the coating during the process [2, 8]. The relationship between the splat diameter $(D)$ and the diameter of the initial droplet $(d)$ for cold spray is given by Lima et al. [10]. The degree of spreading $(D / d)$ is directly proportional to the velocity and inversely proportional to the yield stress $\left(\sigma_{\mathrm{y}}\right)$ of the particle as: $(\mathrm{D} / \mathrm{d}) \alpha\left(\varrho, \mathrm{v}_{\mathrm{p}}, \mathrm{d}\right) \alpha^{-1}\left(\sigma_{\mathrm{y}}\right)$, where $\varrho, \sigma_{\mathrm{y}}$ and $\mathrm{v}_{\mathrm{p}}$ are the density, yield stress and the particle impact velocity, respectively. Hence, the particles with the same yield stress, density and approximately same size will present larger spreading for higher velocities of impact. So there will be smoother coatings with high impact velocities, which rises with the rise of temperature of the gas. Hence, Lima et al. [10] reported the decrease of roughness, increase of deposition efficiency, microhardness and elastic modulus of the cold spray coating with the rise of the gun temperature and also with decrease of spray distance for Ti cold spray coatings on aluminium pipes. Dickinson et al. [8] noticed the increase of splat adhesion with rise of pressure from $0.4 \mathrm{MPa}$ to $1 \mathrm{MPa}$ cold sprayed $\mathrm{TiO}_{2}$ particles on a stainless steel substrate. Also results shows that smaller splats $(<5 \mu \mathrm{m})$ had higher adhesion strengths than larger splats $(>5 \mu \mathrm{m})$. Also the low yield 
strength of aluminum and copper may be one of the reasons of highly dense and low porosity of their cold spray coating [10].

\section{Effect of particle diameter}

The particle velocity is inversely related to particle diameter as: $\mathrm{Vp}=\mathrm{k} / \mathrm{d}^{\mathrm{n}}$, where $\mathrm{Vp}$ is the particle velocity, $\mathrm{k}$ and $\mathrm{n}$ are the coefficients related to driving gas conditions for a certain material [15]. The dependence of $\mathrm{Vp}$ on the particle diameter under different spray conditions of temperature, pressure for nitrogen $(\mathrm{C} 1,2,3)$ and helium $(\mathrm{C} 4)$ gas is shown in Fig.8 for copper powder [16]. The converging-diverging de Laval nozzle with throat diameter $2 \mathrm{~mm}$, expansion ratio 9 and downstream length $100 \mathrm{~mm}$ is used with same carrier and main gas. It is shown that particle velocity decreases for all conditions with increase of particle diameter and decrease is remarkable when particle size is small particularly in the range of $20 \mu \mathrm{m}$ [15].

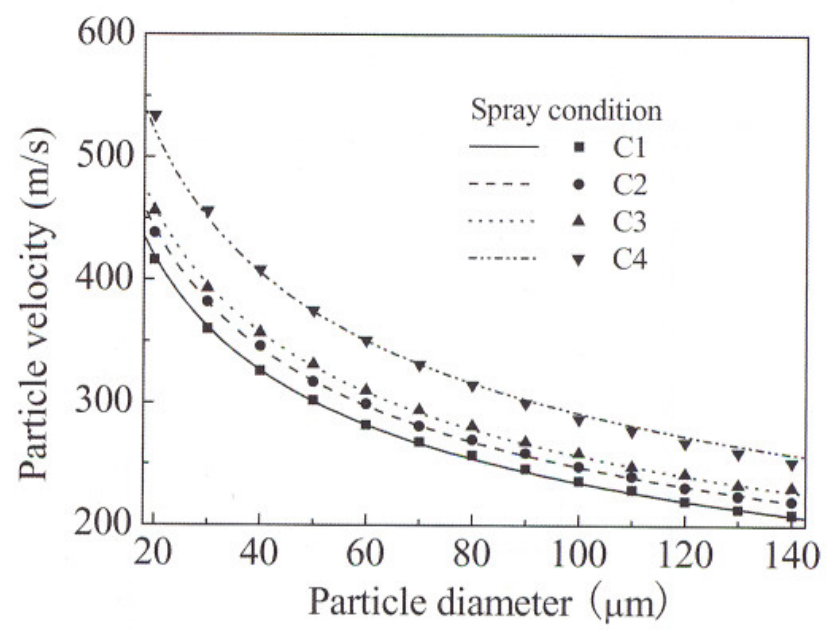

Figure 8: Particle velocity vs. Particle diameter for different gas conditions [15].

\section{Nature of carrier gas}

Regarding carrier gas type, though pre-heated nitrogen gas is used for a wide diversity of materials, but other hard materials cannot be deposited with nitrogen gas because higher velocity is required. Helium provides therefore a solution since it is inert and allows reaching the highest particle velocity. Yoon et al. [17] reported the enhancement of deposition efficiency when process gas changed from nitrogen to helium during cold spraying of NiTiZrSiSn amorphous powder. It is reported by $\mathrm{Li}$ et al. [16] that under all conditions the particles accelerated to higher velocity using helium as compared to nitrogen as driving gas. Helium is however 10 times more expensive than nitrogen, making it economically unviable for many applications unless recycled. However, a Helium Recovery System (HRS) installed at Canada, recovers helium from the cold spray chamber with sufficient purity $(>99 \%)$ allowing for a cost-effective operation by insuring a recovery rate of above $85 \%$ [18].

In some applications mixture of helium $(\mathrm{He})$ and nitrogen $\left(\mathrm{N}_{2}\right)$ is used as carrier gas. Nitrogen $\left(\mathrm{N}_{2}\right)$, being a diatomic gas, and its addition into He increases the enthalpy of the carrier gas for better heat-transfer with spray particles, but it also reduces the velocity due to the heavier atomic mass resulting in coatings with reduced density and hardness[19]. However, high corrosion resistance is reported by Balani et al. [19], for cold spray of $1100 \mathrm{Al}$ onto $1100 \mathrm{Al}$ substrate using He-20 vol. $\% \mathrm{~N}_{2}$ as carrier gas compared to 100 vol. $\%$ He processed coating, though both the cold-sprayed coatings were more corrosion resistant compared to the $1100 \mathrm{Al}$ substrate and coating by $100 \mathrm{vol} . \% \mathrm{He}$ is more hard and dense.

\section{Effect of temperature}

The velocity of the gas at the throat $(\mathrm{Vt})$ of the Laval nozzle is also a function of its temperature as: $\mathrm{Vt}=(\gamma \mathrm{RTt})^{0.5}$, where $\gamma$ is the ratio of gas specific heats, $\mathrm{R}$ is the specific gas constant, $\mathrm{Tt}$ is the gas temperature at the throat, respectively[10]. Hence the particle velocity increases with an increase in gas temperature. Though, gas pre-heating provides higher particle velocity but it also raises the risk of oxidation and/or nitridation which in turn can be detrimental for the design functionality of applied coatings[18]. However, it is also reported that at higher temperatures the gas 
density and viscosity will decrease and hence the drag force of the gas, which is the force responsible for particle acceleration should decrease at higher gas temperatures and hence this area needs to be further explored[10].

It is also reported that critical velocity $(\mathrm{Vc})$ decrease with the increase in the particle temperature by about $14 \mathrm{~m} / \mathrm{s}$ with a temperature increment of $100^{\circ} \mathrm{C}$, due to the thermal softening effect, shown in Fig.9, [16].

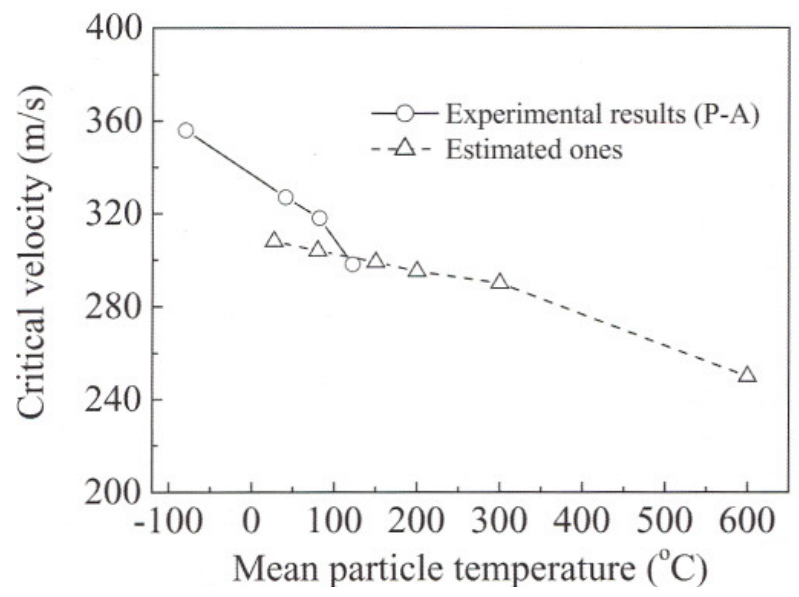

Figure 9: Critical velocity vs. Mean particle temperature [16]

\section{Effect of oxidation condition}

$\mathrm{Li}$ et. al.[14], has reported the dependence of critical velocity on the particle oxidation conditions. It is reported that the large discrepancy among the critical velocities for copper particle can be attributed to the difference in oxygen content of the copper powder. The results as shown in Fig.10 showed that with copper powder the critical velocity $(\mathrm{Vc})$ changed from about $310 \mathrm{~m} / \mathrm{s}$ at an oxygen content of $0.02 \mathrm{wt} . \%$ to $610 \mathrm{~m} / \mathrm{s}$ at an oxygen content of $0.38 \mathrm{wt} . \%$ and with nickelbased Monel alloy, the critical velocity was increased from 583 to $632 \mathrm{~m} / \mathrm{s}$ as the oxygen content was changed from 0.016 to $0.108 \mathrm{wt.} \%$. The study revealed that at high oxygen content, sprayed particles need to break and extrude the oxide scale on impact, therefore the critical velocity is dominated by oxide on the powder and is independent of the material properties as compared to low oxygen content materials.

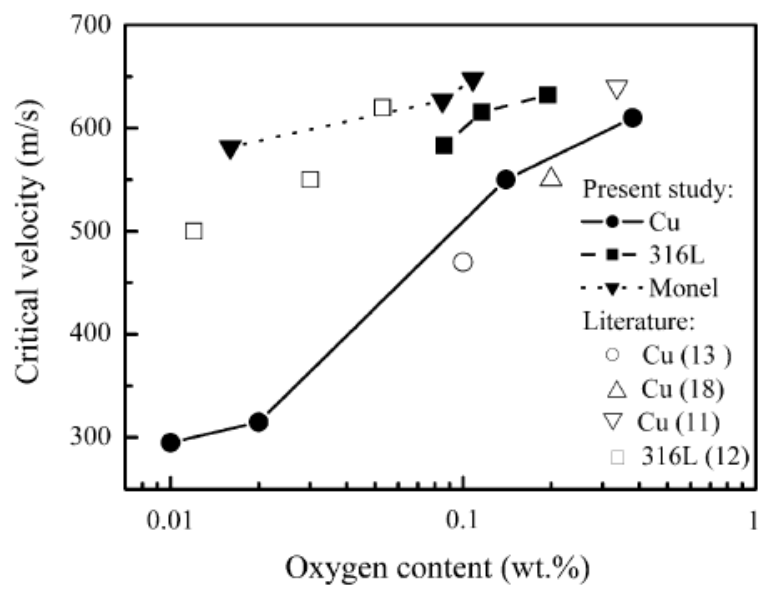

Figure 10: Effect of oxygen content on the critical velocity of different spray materials [14].

\section{Effect of Norzle Design}

However, improvements in nozzle design using gas dynamic models have lead to higher deposition velocities and the ability to deposit larger particles, which results in denser coatings and higher deposition efficiency. So the particle velocity is also influenced by the nozzle design like its nozzle inlet diameter, throat diameter, exit diameter or expansion ratio (i.e., the ratio of the area of the exit to the throat), the entrance convergent section length (upstream length)and the divergent exit length(downstream length). It is found that increasing the length of the nozzle has a significant effect on particle 
velocity. It is examined that the calculated velocity of a $12 \mu \mathrm{m}$ copper particle can be increased from $553 \mathrm{~m} / \mathrm{s}$ to $742 \mathrm{~m} / \mathrm{s}$, with a $33 \%$ increase in particle velocity by increasing the length of the nozzle from $83 \mathrm{~mm}$ to $211 \mathrm{~mm}$, with nitrogen as the carrier gas. This increased velocity leads to an increase in the deposition efficiency from less than $10 \%$ to close to $80 \%$. However, there are fabrication and material constraints that limit the practical length of the nozzles. So new materials need to be tried to improve powder flow through the nozzle and optimization in design is required to minimize the gas flow through the nozzle [20]. Karthikeyan [21] used specially designed tungsten carbide nozzle for coating on a special alloy GRCop-84 and Champagne et al. [22] successfully used thermoplastic nozzle to mitigate the effect of clogging of steel nozzle by Al particles. Fig. 11 shows the optimum value of $5 \mathrm{~mm}$ of nozzle exit diameter for maximum acceleration of particles with different diameters using nitrogen gas at a pressure of $2 \mathrm{MPa}$ and temperature of $300^{\circ} \mathrm{C}$.

$\mathrm{Li}$ et al. [23], designed a short cold spray gun nozzle for applications in limited internal diameters and calculated the optimal design of expansion ratio of 6.25 with nozzle divergent section length of $40 \mathrm{~mm}$ for nitrogen or helium gas at the standoff distance of $30 \mathrm{~mm}$ and found that dense coating can be deposited by the designed short spray gun.

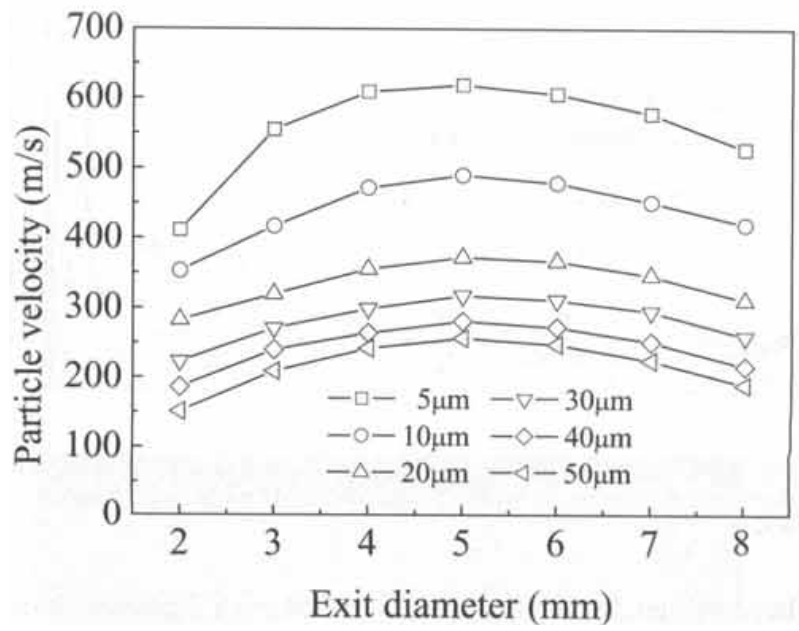

Figure 11: Effect of nozzle exit diameter on velocity of particles of different sizes using nitrogen at a pressure of $2 \mathrm{MPa}$ and temperture of $330^{\circ} \mathrm{C}[23]$

\section{Effect on Microstructure}

The particle velocity $(\mathrm{Vp})$ also affects the microstructure of the cold sprayed coating . The first layer of the particles on the surface is tamped or ram down hard by the high velocity particles for successive layer and the top layer remain porous as compared to inner region having dense microstructure. The thickness of this top porous layer is influenced by the spray conditions, material properties and the morphology of the particles. Since this particle velocity greatly increased with helium as accelerating gas as compared to nitrogen gas under the same operating conditions, so a better tamping effect is reported by Li et al. [13] with helium gas, resulted in a thinner top layer than using nitrogen. It is also reported the large top porous layer of titanium coating by cold spray using nitrogen as accelerating gas; even though the deposition efficiency is larger than $80 \%$.

\section{DEPOSITION EFFICIENCY}

$\mathrm{D}$ eposition efficiency (DE) is one of the most important characteristics of the cold spray coating process. It is the efficiency of deposition of spray powder on the substrate surface and it is practically impossible to obtain $100 \%$ deposition efficiency [7], due to the complicated nature of this spray process. Deposition efficiency can be calculated experimentally as $\mathrm{kd}=\Delta \mathrm{ms} / \mathrm{Mp}$ where $\Delta \mathrm{ms}$ is change of weight of a substrate and $\mathrm{Mp}$ is weight of all particles interacting with a substrate [7]. DE depends upon many factors: delay time, angle of impact of spray particles on the substrate surface, critical velocity, spray powder morphology and substrate surface characteristics like area of the contact surface, crater depth, plastic strain, yield stress, pressure and temperature at the contact boundary, etc [7]. One of the important factors which effect the deposition of particles on the substrate or DE, is the critical velocity Vc. As practically, only the particles having reached a velocity larger than the critical velocity can be deposited to produce coating. Therefore, the critical velocity and particle velocity prior to impact determine the deposition efficiency under a given spray 
condition[14]. However, the spray powders used are mostly polydisperse powders having particles of varying diameter from minimum diameter (dmin.) to maximum diameter (dmax.) [15] and as discuss before the particle velocity is inversely related to particle diameter, hence, particle with dmin. will achieve maximum velocity (Vmax.) and with dmax will achieve minimum velocity (Vmin.). Now if Vmin. is more than $\mathrm{Vc}$ then all the particles in the spray powder will be deposited with $100 \%$ DE and if Vmax. is less than Vc then no deposition with $0 \%$ DE. The maximum size of the particles (dc) that can be adhered to the substrate is: $\mathrm{d}_{\mathrm{c}}=(\mathrm{k} / \mathrm{Vc})^{1 / \mathrm{n}}$, where $\mathrm{Vc}$ is the critical velocity for the particle to be deposited for a certain material[15]. The relationships between the deposition efficiencies and particle velocity is shown in Fig.12 [7]. These calculations of particle velocity are for normal angle between nozzle axis and substrate. As the spray angle decreases from the normal angle called off-normal angle $(\theta)$, then deposition of particle depend upon the normal component of the velocity and only the particles with the normal velocity components higher than the Vc will be deposited during impact as: $\mathrm{dc}=(\mathrm{k} \sin (\theta) / \mathrm{Vc})^{1 / \mathrm{n}},[15]$. The variation of DE with angle is shown in Fig.13.

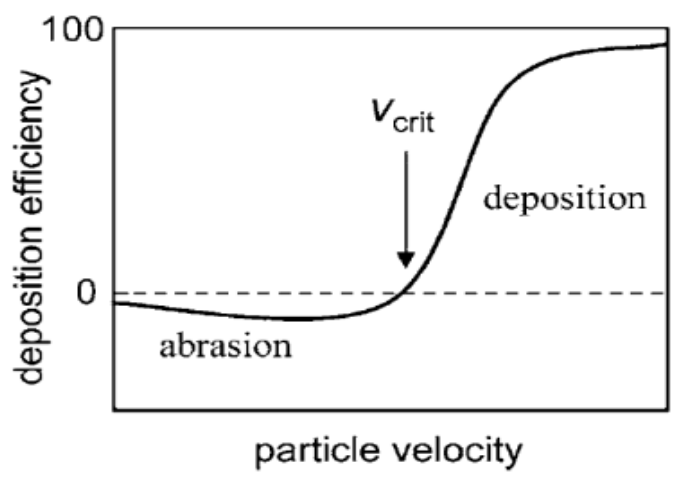

Figure 12: The effect of particle velocity on deposition efficiency (DE) in CS [7].

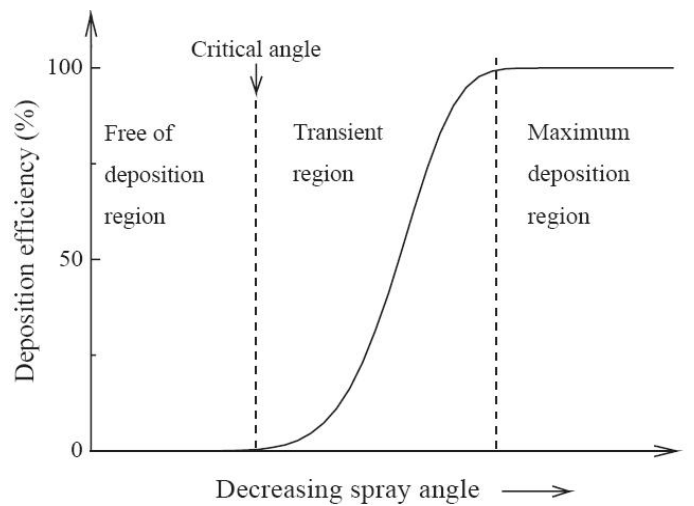

Figure 13: Effect of spray angle on deposition efficiency (DE) [7].

\section{Effect of material properties on DE}

The deposition of particles and DE also depends upon the plastic behavior of the particles and substrate and it is more for metals with high plasticity and the particle adhesion is assumed to be possible if the particle is substantially more plastic than the substrate [7]. Metals with the FCC lattice are highly plastic due to more number of slipping planes, hexagonal structure have much fewer slipping planes, which yield a lower plasticity; and metals with the BCC lattice have the lowest plasticity among the three types. During the impact the particle temperature raised to the glass transition temperature $(\mathrm{Tg})$ of the amorphous alloys, leading to particle softening and making it possible to achieve very high densities in the coating. It is also reported that for the soft substrates and hard particles, the first impacts will primarily confine the deformation to the substrate material, and after the first layer of undeformed hard particles are created the subsequent impacts provide severe plastic deformation on both substrate and impacting particles [7]. Though it is a general postulate that as the substrate deformability decreased, the ease with which particles bond to the surface also decreased, as reported by Ghelichi et al. [7], but completely opposite results are also reported and bonding for $\mathrm{Al}$ particles are seen to be rapid on metallic surface with hardness higher than that of the particles, even when deformation of the substrate was not visible [7]. 
Effect of temperature on DE

The other important parameter is the particle and substrate temperatures; as the air temperature in the pre-chamber increases, both the particle velocity and the particle and substrate temperatures increase which effects the deposition efficiency, as higher deposition rate of $\mathrm{Cu}$ particles was noticed for higher substrate temperature, even under the condition where particles were kept at room temperature [7]. The increase in deposition efficiency is reported by Li et al. [13] with increase in temperature of carrier gas. During study on titanium powder, no particle deposition occurred for temperature of nitrogen gas below $155^{\circ} \mathrm{C}$ and the deposition efficiency increased quickly, especially when the nitrogen temperature becomes higher than $215^{\circ} \mathrm{C}$ [13]. Lima et al. [10] noticed no change in the deposition efficiencies with the rise of gun temperatures from 370 to $480^{\circ} \mathrm{C}$, for Ti coatings on $\mathrm{Al}$ pipes.

\section{Effect of surface condition on DE}

It has also been reported by Ghelichi et al.[7] that with a greater roughness of the substrate surface (going from polished to grit-blasted), deposition efficiency of metallic powders increases because the impacting particles get deformed more severely on roughened surface as compared to smooth surface of the substrate, which enhanced the mechanical interlocking. Kumar et al. [24] suggests that the substrate roughness whose crest size is same as particle size and the trough size is half the particle size creates better bonding. Hence, the bond strength values for grit-blasted substrates are higher. So, during cold spray process to improve adhesion, sand blasting is commonly used like other thermal spraying. However, in this spraying process, during delay time the surface is exposed to a large number of particle impacts before particles start to adhere to the surface. So these impacts of the sprayed particles can play an important role for preparation and activation of the substrate surface and this effect can be used in replacing the sand blasting, where it is unacceptable like in spraying on parts with thin walls, parts already coated and parts made of brittle materials and also the effect of interface contamination due to penetration of sand blasting particles into the substrate, especially for soft substrate materials can be avoided [7]. Kumar et al. [24] also suggests the need of further research to optimize the roughness value for different materials.

\section{APPLICATIONS OF CS}

C old spray technology is not here to replace any of the well-established thermal spray methods. Instead, cold spray technology is expected to supplement and expand the range of applications for thermal spray [1]. CS applications include both production and restoration [6] in the field of medical, aerospace, electronics, automotive and petrochemical industries [25]. Any defect may be easily removed by this process to save production quality. One of the important applications is the repair of the casting defects. Both casting defects and machining defects removal by this process can save small-batch or unique production. Also casting moulds restoration or modification become easy with this process.

$\checkmark$ CS is also widely used for the restoration of antique objects both technical as cars and airplanes, and art as metal sculptures [6]. It is used in aerospace industry for aluminum and aluminum alloy coatings for repair/refurbishment of space shuttle solid rocket boosters, in aircraft industry for repair and retrieval of parts and plate stocks used in aircraft structures, repair/refurbishment of casings in gas turbines, corrosion protection coatings in petrochemical, and anti skid coatings [2], sealing up the leakages, shape restoration, defects elimination at small automotive workshops, like repair of vehicle platforms [6]. It is also used for spraying of copper alloys on 'touch' surfaces which are frequently in human contact, such as door knobs, light switches, faucets, bed rails, food preparation areas and other hardware[25]. The continuous seamless titanium pipes can be directly manufactured using Cold Spray coating technique.

$\checkmark$ CS coatings are successfully applied to welding lines after the welding of hot galvanized metal structures, anti seizure coatings coats the screws at oil-well tubing and at marine ship propeller shaft. This process is also used for unique coatings to special heating glasses for ships, airplanes and railroad locomotives. Also elements of optical electronic devices are created by cold spray[6]. The restoration of defected or worn bearing seats by this process allows avoiding the replacement of the scarce or expensive parts. It is also used to remove defects at the surfaces of the huge rolls for paper and polyethylene film production. Hence, the service of worn and old equipment becomes much easy and simple with the use of cold spray process[6].

$\checkmark$ Cold spray technique is used to fabricated the Al-tube heat exchanger, used as air conditioning equipments for all types of vehicles these days. It is observed by Yoon et al.[26] that high quality coating, which has high corrosion resistance with good brazeability as compared to conventional methods can be obtained by CS process and also with less manufacturing cost. 
$\checkmark \quad$ Al-Sn alloys are widely used as sliding bearing materials in automobile and shipbuilding industry. Tin is a necessary soft phase in the aluminum matrix which can provide suitable friction properties and shear surface during sliding. But due to deleterious effects of high temperature of other thermal processes there is coarsening of Sn in the coating. Ning et al. [27] successfully prepared Al-5Sn and Al-10Sn coatings by CS process, with low porosity and well bonded dense structures and fraction of $\mathrm{Sn}$ phase is consistent with the feedstock powder. Al-5Sn coating can be deposited by high pressure cold spray with nitrogen while Al-10Sn can only be deposited by low pressure cold spray with helium gas. [30]

$\checkmark$ CS can also be used for the fabrication of complex conductive patterns in solar cells, to enhance surface performance in components made of advanced polymer-matrix composites in wind power generation. Architects can create aesthetic metallic patterns on any metal or ceramic substrate by this process [1].

$\checkmark \quad$ In the medical field, cold spray has already been demonstrated to effectively apply hydroxyapatite (Ca10(PO4)6(O $\mathrm{H}) 2$, also known as (HAP), to a number of substrates [1]. HAP is widely used in dental and orthopedic implants, due to its chemical and crystallographic similarity with bone minerals and due to lack of cytotoxic effects it can be bonded to the bone directly. But due to poor mechanical strength, the combination of bioactive HAP coating and mechanically strong metals is used for surgical implants. Though this bioceramic coating is usually done by plasma spray technique, but with deleterious effects of high temperature in the plasma, hence low temperature cold spray coating can remove these harmful effects. The composite coating of Ti-HAP is successfully deposited using 'CGT Kinetiks 4000 cold spray system' at ASB industries, Ohio, with bond strength comparable or better to that of plasma sprayed coating and it is reported that dense composite coatings, containing up to $30 \%$ HAP can be deposited by this technique. Hence the cold spray process has matured from an emerging technology to a viable alternative to thermal spray for selected applications $[3,28]$.

$\checkmark$ Cold spray technology is successfully used to develop high temperature oxidation resistant $\mathrm{CuCrAl}$ and $\mathrm{NiCrAlY}$ coatings on GRCop-84 substrates, at ASB Industries, Ohio, using specially designed tungsten carbide nozzle. GRCop-84, a Cu-8CR-4Nb alloy, developed at NASA Glenn Research Center (GRC),for rocket engine liner applications, having very high temperature creep and fatigue capabilities. But for their maximum life additional oxidation protection is required to prevent blanching [21].

$\checkmark$ CS is used for application of aluminimum barrier coatings for protection from high rate of corrosion and also to restore dimensional tolerances of heat-sensitive materials such as $\mathrm{Mg}$ alloys ZE41A-T5 used in the fabrication of transmission gearboxes in helicopters and fixed-wing aircraft like UH-60 Seahawk and MH-60S Seahawk. But Mg alloys are highly susceptible to galvanic corrosion when coupled to another metal, because magnesium being the most electrochemically active structural metal. Also these alloys are very susceptible to damage from excess heat and if coated by conventional thermal spray methods like HVOF, then magnesium can reacts with molten material deposited,[22, 29].

$\checkmark$ Cold spray coatings are being used in the power generation plant. These are applied on the boiler tubes to provide resistance from the high temperature corrosion, to provide resistance from the cavitation wear of turbine blades, and the water pump housing, impeller fins, impeller seal section and wear rings. The cold spray of tungsten carbide, chromium oxide and Ni-Cr coatings can be applied on these parts. Also wear rings can be reconditioned by applying bronze by this low temperature spray process. The chromium carbide can be applied to the journal used in coal crusher[30].

$\checkmark$ One of the important application of cold spray is the coating of copper powder on the aluminium tips of the electric mains to prevent the electrochemical oxidation of contacting elements of copper wire of the transformer and aluminium tip of the cable. The presence of different materials results in circuit breakdown and can be prevented by this method. This problem also occurs in the automotive batteries with contact of copper wire and the aluminium battery terminal[30].

\section{Nanostructured Coating and smart structures}

Cold spray can be also be used to embed micro-sensors, along with functional coatings, on surfaces for smart structures. These structures would have the ability to provide real-time information related to materials performance or environmental conditions[1].

Cold spray can effectively be used for nanostructured coating without compromising their beneficial microstructure. Nanostructured (or nanocrystalline) materials have achieved much attention in recent years due to their outstanding properties like having having higher hardness, strength and corrosion resistance as compared to those of micron-size counterparts. These materials are characterized by a microstructural length scale in the1-200 nm regime. It is found that these are sensitive to process temperature because particle size strongly influences the particle thermal history as small 
particles rapidly heat up and also rapidly cool down. It also affects the interlamellar adhesion of the splats and hence influencing mechanical properties of the coating. Nano structured WC-Co cermets coatings shows better wear resistance due to the increase of hardness of coatings by the decrease in the particle size of the feedstock powder [31]. Jianhong et al. [32] found that the nanostructured coating of $\mathrm{Cr}_{3} \mathrm{C}_{2}-25(\mathrm{Ni20} \mathrm{Cr})$ exhibits a $20.5 \%$ increase in microhardness of 1020 HV300 as compared with the corresponding conventional coating of $846 \mathrm{HV}_{300}$. Also these coatings consists of a ductile and a brittle phase that has high potential to improve the corrosion resistance even in the almost hopeless case of high temperature corrosive environment.

However, the main hurdle in the nano powder coating is the spray technique, due to the requirement of heating by other thermal spray process like HVOF and plasma spray, the properties of nano-sized particles changed. During nano-powder coating by thermal spray process, the feed stock material should exhibit a nanosized structure to get the properties of a nano-structured coating after the spray process. The processing of a nanopowder by means of the standard thermal spray procedure, first of all requires the agglomeration of the nanopowders, in order to form spray particles with appropriate grain size that are suitable for a standard powder feeding device. The agglomerated particles lose their nanostructure, so it is not yet clear if there is any benefit of using nanostructured feed stock materials as compared to using conventional powders. Also due to decreasing particle size, the fluidization of the spray powder gets more and more challenging, so it is difficult to decrease the coating thickness below a value in the range of $30 \mu \mathrm{m}$ by thermal spray process and a reduction of particle sizes in the nano range of below $5 \mu \mathrm{m}$ needs improvement in powder feeding technique [31].

Therefore, cold spray coating technique, being a low temperature and also a solid state process, is foreseen as a viable solution to development of nano-structured coatings, using cold spray process [9, 31, 33, 34]. During the last two decades, research and development on cold spray process and technology, leads to significant progresses on both coating process and technologies $[14,33]$. With such progresses, most metals and their alloys can be deposited by cold spraying including coatings using nanostructured powders like cermets WC-Co which is a most important wear-resistant coating materials. Nanostructured WC-12Co coatings are deposited successfully by cold spraying using a nanostructured feedstock with $1800 \mathrm{Hv} 0.3$ microhardness of sprayed coating, with critical velocities of about $915 \mathrm{~m} / \mathrm{s}$ is reported, by nozzle of downstream length $100 \mathrm{~mm}$, throat diameter of $2 \mathrm{~mm}$ and exit diameter of $4 \mathrm{~mm}$, standoff distance $20 \mathrm{~mm}$ and using helium gas at $2 \mathrm{MPa}$ pressure and $600^{\circ} \mathrm{C}$ temperature in the prechamber [33]. Lima et al. [9] produce pure and well bonded nanostructured WC- $12 \%$ Co coatings on low carbon steel substrate via cold-spray processing. The coating has a high density and around $1225 \mathrm{kgf} / \mathrm{mm}^{2}$ Knoop microhardness compared to around $42 \mathrm{kgf} / \mathrm{mm}^{2}$ of the nanostructured feedstock i.e around $2800 \%$ increase. The impact of the particles against the substrate at supersonic velocities, promotes a densification in each nanostructured particle, without the presence of porosity. However there is no significant difference between the average grain size of the nanostructured feedstock $109 \mathrm{~nm}$ and coating $103 \mathrm{~nm}$ is reported in the study [9]. Hence, the ability of cold spray process to deposit advanced materials onto a diversity of substrates will define the direction and opportunities lying ahead for this technology [1].

\section{CONCLUSION}

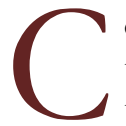

old spray technology is an emerging technology and it should be clear that it is not here for replacement of any of the well-established thermal spray methods. Instead, cold spray technology is expected to supplement and expand the range of applications for thermal spray processes as a greener alternative according to stringent environmental and health safety regulations. A number of materials have already proven to be suitable for deposition by cold spray from decorative articles to biomedical, automotive, power plants and space industries. Extensive research is required to design the optimum parameters like nature of gas, temperature control, nozzle design and its material and also prediction of critical velocity for different particle/substrate combinations. The research area of mathematical modeling to optimize various design parameters is still open to expand this process to more non-traditional applications. Research is required on deposition of hard and brittle ceramic materials by cold spray.

The cold spray coating process has huge potential of growth with more applications in new areas like in boiler industry, to increase the life of boiler tubes by prevention from high temperature corrosion in aggressive chlorine and sulphate based environments. Coatings by cold spray technique can be beneficial for protection from high temperature oxidation failure of boiler tubes especially of waste-to-energy plants, which are still running at very less efficiency as compared to fossil fuel based plants. This area is explored by the author with a project sponsored by UGC, Govt. of India and in collaboration of ASB Industries Ohio and results will be published in future. It is expected that this decade will saw exponential growth of cold spray technology around the globe, through the development of CS coatings for specific applications. 


\section{ACKNOWLEDGEMENT}

A

uthor 'Harminder Singh' thankfully acknowledge the research grant under UGC Minor Project from UGC, New Delhi, Govt. of India, for carrying out this R\&D work on "Studies on the behavior of coatings in improving the resistance to hot corrosion degradation in waste incineration environment", vide F.No. 39-1003/2010(SR).

\section{REFERENCES}

[1] Villafurerte Julio, Current and Future Applications of Cold Spray Technology, Metalfinishing (2010)

[2] J. Karthikeyan, Cold spray technology:International status and USA efforts, report by ASB Industries (2004).

[3] A. Choudhuri, P.S. Mohanty, J. Karthikeyan, Bio-ceramic Composite Coatings by Cold Spray Technology asbindustries paper 22241 manuscript 3762, (2008).

[4] E. Tinashe Sanyangare, Conceptual Design of a Low Pressure Cold Gas Dynamic Spray (LPCGDS) System, M.S Thesis, (2010).

[5] J. Karthikeyan, Advanced Materials and Processes (2006)

[6] A. Shkodki, Pecularities of the Gas Dynamic Spray Applications in Russia, OCPS, Russia, (2010).

[7] R. Ghelichi, M. Guagliano, Frattura ed Integrità Strutturale, 8 (2009) 30.

[8] M. E.Dickinson, M. Yamada, Nanoscience and Nanotechnology Letters, 2(4) (2010) 348.

[9] R. S. Lima, J. Karthikeyan, C. M. Kay, J. Lindemann, C. C. Berndt, Thin Solid Films, 416 (2002) 129.

[10] R. S. Lima, A. Kucuk, C. C. Berndt, J. Karthikeyan, C. M. Kay, J. Lindemann, Journal of Materials Science Letters, 21 (2002) 1687.

[11] V. K. Jr.Champagne, D. Helfritch, P. Leyman, S. Grendahl, B. Klotz, Journal of Thermal Spray Technology, 14(3) (2005) 330.

[12] R. Lupoi, W. O'Neill, Surface \& Coatings Technology, 205 (2010) 2167.

[13] C.-J. Li, W.-Y. Li, Surface and Coatings Technology, 167 (2003) 278.

[14] C.-J. Li, H.-T. Wang, Q. Zhang, G.-J. Yang, W.-Y. Li, H. L. Lio, J. of Thermal Spray Technology 19(1-2) (2010) 95.

[15] C.-J. Li, W.-Y. Li, Y.-Y. Wang, G.-J. Yang, H. Fukanuma, Thin Solid Films, 489 (2005) 79.

[16] C.-J. Li, W.-Y. Li, H. Lio, J. of Thermal Spray Technology, 15(2) (2006) 212.

[17] S. Yoon, C. Lee, H. Choi, H. Jo, Materials Science and Engineering, 415 (2006) 45.

[18] S. Desaulniers, Polycontrols, 2010.

[19] K. Balani, A. Agarwal, S. Seal, J. Karthikeyan, Scripta Materialia 53 (2005) 845.

[20] www.psu.edu (2011)

[21]J. Karthikeyan, Development of Oxidation Resistant Coatings on GRCop-84 Substrates by Cold Spray Process, NASA/CR-2007-214706, (2007).

[22] V. K. Champagne, P. F. Leyman, D. J. Helfritch, Magnesium Repair by Cold Spray, ARL report no. ARL-TR-4438, (2008).

[23] W.-Y. Li, C.-J. Li, J. of Thermal Spray Technology, 14(3) (2005) 391.

[24] S. Kumar, G. Bae, C. Lee, Applied Surface Science 255 (2009) 3472.

[25] M. Trexler, Cold Spray Technology Application, ARL, USA, (2010).

[26] S. Yoon, H. Kim, C. Lee, Surface \& Coatings Technology, 201 (2007) 9524.

[27] X.-J. Ning, J.-H. Kim, H.- J. Kim, C. Lee, Applied Surface Science, 255 (2009) 3933.

[28] J. Cizek, K. A. Khor, On Cold Kinetic Spraying of Hydroxyapatite and TiO2 Bioceramics onto Ti-6Al-4V and Glass Substrates, (2008).

[29] B. DeForce, T. Eden, J. Potter, Application of Aluminum Coatings for the Corrosion Protection of Magnesium by Cold Spray, ARL report, 2008.

[30] T. Goyal, T. S. Sidhu, R. S. Walia, In: National Conference on Advancements and Futuristic Trends in Mechanical and Materials Engineering, (2010) 364.

[31] H. Singh, T. S. Sidhu, S. B. S. Kalsi, Journal on Electronics Engineering, 1(1) (2010) 1.

[32] Jianhong He, Julie M. Schoenung, Nanostructured coatings, Materials Science and Engineering 336 (2002) 274.

[33] Li Chang-Jiu, Yang Guan-Jun, Gao Pei-Hu, Ma Jian, Wang Yu-Yue, Li Cheng-Xin, Characterization of Nanostructured WC-Co Deposited by Cold Spraying, Journal of Thermal Spray Technology 16(5-6) (2007) 1011. 
[34] Singh Harminder, Sidhu T.S., Kalsi S.B.S., Scarcity of energy and Waste-to-energy (WTE) plant: A Review, imanager's Journal on Mechanical Engineering 1(1) (2011) 1.

[35] Sidhu T.S. PhD Thesis, 2006. 